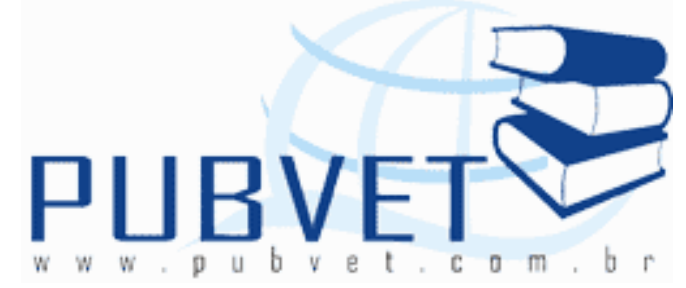

PUBVET, Publicações em Medicina Veterinária e Zootecnia.

\title{
Limitações de fertilidade do solo para o crescimento de Brachiaria brizantha cv. Xaraés em Latossolo Amarelo
}

Newton de Lucena Costa ${ }^{1}$, Claudio Ramalho Townsend ${ }^{2}$, Valdinei Tadeu Paulino $^{3}$, Lucia Elenícia da Silva Nascimento ${ }^{4}$, João Avelar Magalhães ${ }^{5}$

${ }^{1}$ Eng. Agrôn., D.Sc., Embrapa Roraima, Boa Vista, RR.

${ }^{2}$ Zootecnista, D.Sc., Embrapa Rondônia, Porto Velho, RO.

${ }^{3}$ Eng. Agrôn., Ph.D., Instituto de Zootecnia, Nova Odessa, SP.

${ }^{4}$ Estudante de Pós-Graduação em Gestão Ambiental e Ecoturismo, Faculdade Montenegro, Parnaíba, PI.

${ }^{5}$ Méd. Vet., D.Sc., Embrapa Meio-Norte, Parnaíba, PI.

\section{Resumo}

Avaliou-se, em casa-de-vegetação, as limitações nutricionais ao crescimento de Brachiaria brizantha cv. Xaraés, em um Latossolo Amarelo, textura argilosa. Utilizou-se a técnica de diagnose por subtração, com oito tratamentos dispostos em blocos casualizados com quatro repetições. Os nutrientes que mais afetaram a produção de matéria seca foram fósforo, potássio, nitrogênio e enxofre, com reduções de 78,2; 49,2; 39,8 e 29,3\%, respectivamente, em relação ao tratamento completo. As omissões de micronutrientes e da calagem foram pouco expressivas. Os maiores teores de fósforo, nitrogênio, cálcio, magnésio e potássio foram obtidos com o tratamento completo. $\mathrm{O}$ fósforo foi o nutriente mais limitante à produção de forragem, com reflexos negativos em sua composição mineral, constituindo-se, portanto, em fator indispensável 
para o estabelecimento de pastagens de $B$. brizantha $\mathrm{cv}$. Xaraés em solos argilosos e de baixa fertilidade natural.

Palavras-chave: cálcio, fósforo, magnésio, matéria seca, nitrogênio, potássio

\title{
Nutritional soil limitations for Brachiaria brizantha cv. Xaraés growth in Yellow Latosol
}

\begin{abstract}
It was evaluated, under greenhouse conditions, the nutritional limitations for the growth of Brachiaria brizantha cv. Xaraés, in a clay Yellow Latosol. It was utilized the diagnosis subtraction technique, with eight treatments in a completely randomized block design with four replicates. The nutrients that most affected dry matter yields were phosphorus, potassium, nitrogen and sulphur, with decreases of $78.2 ; 49.2 ; 39.8$ and $29.3 \%$, respectively, in relation to the treatment complete. Subtraction of micronutrients and liming were not limiting to grass forage production. The higher phosphorus, nitrogen, calcium, magnesium and potassium contents were obtained with the treatment complete. These data indicated that to increase grass forage production only phosphorus, nitrogen and potassium are needed as fertilizers.
\end{abstract}

Keywords: calcium, dry matter, magnesium, nitrogen, potassium

\section{Introdução}

Na Amazônia, a maioria dos solos apresenta baixa fertilidade natural, caracterizados por elevada acidez, baixa capacidade de troca catiônica e altos teores de alumínio trocável, o que limita a produtividade das pastagens cultivadas, implicando num fraco desempenho zootécnico das pecuárias de carne e/ou leite (COSTA \& PAULINO, 2007). Ademais, via de regra, as pastagens são estabelecidas em solos exauridos por sucessivos cultivos anuais (arroz, milho, feijão e mandioca), o que acelera os processos de sua degradação (COSTA et al., 2004). 
Segundo Santos et al. (2009), o conhecimento dos fatores nutricionais limitantes ao crescimento das gramíneas forrageiras é de grande importância para o estabelecimento, manejo e persistência das pastagens cultivadas. Em ensaios exploratórios de fertilidade de solo realizados em Rondônia, constatouse que o fósforo $(P)$, seguido do enxofre $(S)$, foram os nutrientes mais limitantes ao crescimento de Brachiaria decumbens, $B$. humidicola e $B$. brizantha cv. Marandu, reduzindo drasticamente seus rendimentos de forragem, teores e quantidades acumuladas de nitrogênio e fósforo (DIAS FILHO \& SERRÃO, 1987; COSTA et al., 1988; COSTA et al., 2004), fato também destacado por Saraiva et al. (1993), Vitor et al. (2009a) e Vitor et al. (2009b) após avaliarem, respectivamente, as gramíneas Melinis minutiflora (capim-gordura), Cenchrus ciliaris var. Áridus e 131, e Panicum maximum cV. IZ-5 (capim-arauana) cultivadas em casa de vegetação.

Deste modo, o presente trabalho teve por objetivo determinar os nutrientes mais limitantes à produção de forragem de Brachiaria brizantha cv. Xaraés.

\section{Material e Métodos}

O ensaio foi conduzido em casa-de-vegetação, utilizando-se um Latossolo Amarelo, textura argilosa, fase floresta, o qual apresentava as seguintes características químicas: $\mathrm{pH}=5,0 ; \mathrm{Al}=1,3 \mathrm{cmol} / \mathrm{dm}^{3} ; \mathrm{Ca}+\mathrm{Mg}=$ $1,9 \mathrm{cmol}_{\mathrm{C}} / \mathrm{dm}^{3} ; \mathrm{P}=3 \mathrm{mg} / \mathrm{kg} ; \mathrm{K}=52 \mathrm{mg} / \mathrm{kg}$ e Matéria Orgânica $=3,88 \%$. O solo foi coletado na camada arável (0 a $20 \mathrm{~cm}$ ), destorroado e peneirado em malha de $6 \mathrm{~mm}$ e posto para secar ao ar.

Utilizou-se a técnica de diagnose por subtração, com oito tratamentos 1 ) testemunha; 2 ) completo $=$ calagem $+\mathrm{N}+\mathrm{P}+\mathrm{K}+\mathrm{S}+$ micronutrientes; 3 ) completo $-\mathrm{N}$; 4) completo $-\mathrm{P}$; 5) completo $-\mathrm{K}$; 6) completo $-\mathrm{S}$; 7) completo micronutrientes e, 8) completo - calagem) dispostos em blocos casualizados com quatro repetições. Quando pertinente, as doses dos nutrientes $(\mathrm{mg} / \mathrm{kg}$ ) aplicadas no plantio e uniformemente misturadas com o solo foram: $\mathrm{N}=40$ (ureia); $\mathrm{P}=50$ (superfosfato triplo); $\mathrm{K}=40$ (cloreto de potássio); $\mathrm{S}=30$ 
(enxofre elementar) e micronutrientes $=15$ (FTE BR-16). O calcário dolomítico $(500 \mathrm{mg} / \mathrm{kg}-$ PRNT $=100 \%)$ foi aplicado 60 dias antes do plantio, sendo o solo nesse período mantido em $80 \%$ de sua capacidade de campo. Cada unidade experimental constou de um vaso com capacidade para 3,0 $\mathrm{dm}^{3}$ de solo seco. Dez dias após a emergência das plantas, executou-se o desbaste, deixando-se três plantas/vaso. Durante o período experimental foram realizados três cortes, a intervalos de 45 dias e a $15 \mathrm{~cm}$ acima do solo.

\section{Resultados e Discussão}

O maior rendimento de MS foi obtido com o tratamento Completo $(14,79$ $\mathrm{g} /$ vaso), seguindo-se o Completo - Micronutrientes (13,50 g/vaso) e Completo - Calagem (12,10 g/vaso). A omissão de P promoveu uma significativa redução $(78,2 \%)$ no rendimento de $M S$, o qual foi semelhante $(P>0,05)$ ao registrado com o tratamento testemunha. Em Manaus, Amazonas, após trabalhar em um Latossolo Amarelo argiloso, Correa et al. (1995) também relataram que a baixa disponibilidade de $P$ no solo foi a mais relevante limitação química no desenvolvimento da Brachiaria humidicola.

Os efeitos decorrentes da retirada de $\mathrm{N}$ e do $\mathrm{S}$ foram menos acentuados que os do $P$, resultando em decréscimos da produção de $M S$ de 39,8 e 29,3\%, respectivamente, enquanto que a omissão de micronutrientes proporcionou uma redução de apenas $8,7 \%$. A ausência do $\mathrm{K}$ implicou em decréscimo de $49,2 \%$ da produção de forragem, em comparação ao tratamento Completo (Figura 1). Da mesma forma, Costa et al. (2004), utilizando o mesmo tipo de solo deste experimento, constataram que as omissões de $\mathrm{P}, \mathrm{S}$ e $\mathrm{K}$ implicaram em reduções de 81,$6 ; 54,3$ e 39,4\%, respectivamente, nos rendimentos de forragem de $B$. brizantha $\mathrm{Cv}$. Marandu. Tendências semelhantes foram relatadas por Dias Filho \& Serrão (1987), Carvalho et al. (1992) e Morikawa et al. (1998) para P. maximum, Melinis minutiflora e B. brizantha cv. Marandu, respectivamente. 


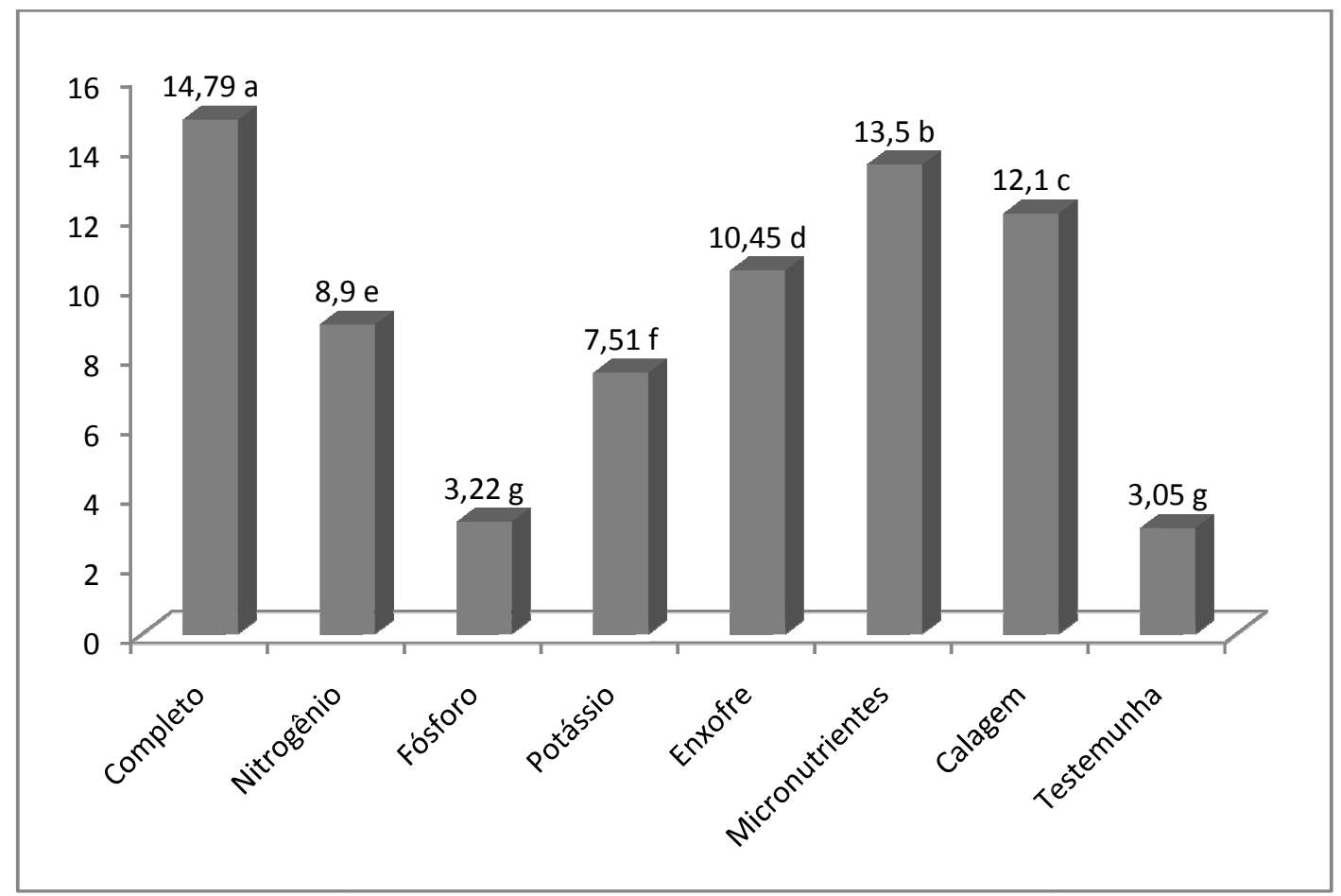

Figura 1. Rendimento de forragem (g/vaso) de Brachiaria brizantha cv. Xaraés, em função da aplicação ou omissão de macro e micronutrirentes.

Os teores de macronutrientes não apresentaram uma tendência definida, em função dos tratamentos, a qual pudesse ser explicada pelo efeito de diluição ou concentração. Os maiores teores de N, P, Ca, Mg e K foram obtidos no tratamento Completo e os menores quando de suas ausências na fertilização da gramínea (Tabela 1 ). A omissão do $P$ resultou em reduções nos teores de $\mathrm{Ca}$ e $\mathrm{K}$, evidenciando o efeito restritivo da baixa disponibilidade de energia para o adequado metabolismo da gramínea. O $\mathrm{P}$ desempenha papel importante na formação do ATP (adenosina trifosfato), principal fonte energética para a planta, atuando nos processos de fotossíntese e respiração, no transporte de assimilados, no armazenamento e transferência de energia, na divisão celular e na transferência de informações genéticas, além de ser componente estrutural dos ácidos nucleicos e de coenzimas, como as fosfoproteínas e fosfolipídeos (TAIZ \& ZEIGER, 2004). Os teores de $P$ registrados em todos os tratamentos, excetuando-se os da testemunha, e os de Ca e Mg obtidos no tratamento Completo, foram superiores aos níveis críticos internos, relacionados com $80 \%$ da produção máxima de forragem, 
COSTA, N.L. et al. Limitações de fertilidade do solo para o crescimento de Brachiaria brizantha cV. Xaraés em Latossolo Amarelo. PUBVET, Londrina, V. 7, N. 20, Ed. 243, Art. 1604, Outubro, 2013.

estimados por Costa et al. $(2003,2004)$ para B. brizantha cv. Xaraés, os quais foram de 1,27; 5,11 e 4,23 g/kg, respectivamente para $\mathrm{P}$, Ca e Mg.

Tabela 1. Teores de nitrogênio, fósforo, cálcio, magnésio e potássio de Brachiaria brizantha cv. Xaraés, em função da aplicação ou omissão de macro e micronutrientes.

\begin{tabular}{|c|c|c|c|c|c|}
\hline Tratamentos & Nitrogênio & Fósforo & Cálcio & Magnésio & Potássio \\
\hline & & & $\mathrm{g} / \mathrm{kg}$ & 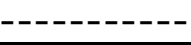 & ------- \\
\hline$\overline{\text { Completo (C) }}$ & $21,98^{a}$ & $1,92^{a}$ & $5,23^{a}$ & $4,77^{a}$ & $15,11^{a}$ \\
\hline C - Nitrogênio & $12,13^{\mathrm{e}}$ & $1,77^{b}$ & $4,11^{c}$ & $3,21^{b}$ & $11,23^{d}$ \\
\hline C - Fósforo & $16,89^{c}$ & $1,38^{\mathrm{e}}$ & $3,07^{d}$ & $4,03^{a b}$ & $10,08^{e}$ \\
\hline C - Potássio & $17,32^{c}$ & $1,49^{d}$ & $4,75^{b}$ & $2,65 \mathrm{bcd}$ & $11,56^{d}$ \\
\hline C - Enxofre & $17,02^{c}$ & $1,71^{b}$ & $5,03^{a b}$ & $2,20^{\mathrm{cd}}$ & 13,67 bc \\
\hline C - Micronutrientes & $19,67^{b}$ & $1,88^{a}$ & $4,98^{a b}$ & $3,44^{b}$ & $14,69^{a}$ \\
\hline C - Calagem & $17,26^{c}$ & $1,60^{\mathrm{c}}$ & 2,79 de & $2,18^{\mathrm{cd}}$ & $12,80^{c}$ \\
\hline Testemunha & $19,04^{b}$ & $1,18^{f}$ & $2,45^{\mathrm{e}}$ & $1,98^{d}$ & $10,14^{\mathrm{e}}$ \\
\hline
\end{tabular}

- Médias seguidas de mesma letra não diferem entre si $(P>0,05)$ pelo teste de Tukey

\section{Conclusões}

$\mathrm{O} P$ é o nutriente mais limitante à produção de forragem, com reflexos negativos em sua composição mineral, constituindo-se em fator indispensável para o estabelecimento de pastagens de Brachiaria brizantha cv. Xaraés.

O N, S e o K também são limitantes, porém com menor intensidade; os efeitos da omissão da calagem foram secundários, enquanto que a ausência de micronutrientes foi pouco expressiva.

\section{Referências Bibliográficas}

CARVALHO, M.M.; BOTREL, M.A.; CRUZ FILHO, A.B. da. Estudo exploratório de um Latossolo Vermelho-Amarelo da zona dos campos das vertentes, MG. Revista da Sociedade Brasileira de Zootecnia, v.21, n.2, p.320-328, 1992.

CORREA, J.C.; REICHARDT, K. Efeito do tempo de uso das pastagens sobre as propriedades de um Latossolo Amarelo da Amazônia Central. Pesquisa Agropecuária Brasileira, v.30, p.107-114, 1995.

COSTA, N. de L.; GONÇALVES, C.A.; OLIVEIRA, J.R. da C. Nutrientes limitantes ao crescimento de Brachiaria humidicola consorciada com leguminosas em Porto VelhoRO. Porto Velho: Embrapa-UEPAE Porto Velho, 1988. 4p. (Comunicado Técnico, 70)

COSTA, N. de L.; PAULINO, V.T. Limitações nutricionais ao crescimento de Panicum maximum cv. Centenário. Pubvet, v.1, n.5, Art\#179, 2007.

COSTA, N. de L.; PAULINO, V.T.; RODRIGUES, A.N.A. Adubação fosfatada em Brachiaria brizantha cv. Xaraés. Porto Velho: Embrapa Rondônia, 2003. 3p (Comunicado Técnico, 262). 
COSTA, N. de L.; PAULINO, V.T.; RODRIGUES, A.N.A.; TOWNSEND, C.R.; MAGALHÃES, J.A. Calagem e adubação de pastagens. In: COSTA, $\mathrm{N}$ de L. (Ed.). Formação, manejo e recuperação de pastagens em Rondônia. Porto Velho: Embrapa Rondônia, 2004. p.80-114.

DIAS FILHO, M.B.; SERRÃO, E.A.S. Limitações de fertilidade do solo na recuperação de pastagem degradada de capim-colonião (Panicum maximum Jacq.) em Paragominas, na Amazônia Oriental. Belém: EMBRAPA-CPATU, 1987. 19p. (Boletim de Pesquisa, 87).

MORIKAWA, C.K.; FAQUIN, V.; CURI, N.; MARQUES, E.S.; WERNEK, M.R.; EVANGELISTA, A.R. Crescimento e produção de gramíneas forrageiras em amostras de Latossolo da região dos Campos das Vertentes-MG, Brasil. Pasturas Tropicales, v.20, n.2, p.18-23, 1998.

SANTOS, L.C.; BONOMO, P.; SILVA, V.B. et al. Características morfogênicas de braquiárias em resposta a diferentes adubações. Acta Scientiarum. Agronomy, v.31, n.1, p.221-226, 2009.

SARAIVA, O.D.; CARVALHO, M.M.;OLIVEIRA, F.T.T. Nutrientes limitantes ao crescimento de capim-gordura em um Latossolo Vermelho-amarelo álico. Pesquisa Agropecuária Brasileira, v.284, n.8, p.963-968, 1993.

TAIZ, L.; ZEIGER, E. Fisiologia vegetal. Porto Alegre: Artmed. 3ed. 2004. 719p.

VITOR, C.M.T.; PORTO, E.M.V.; SILVA, M.F.; LIMA, M.V.G.; PEREIRA, M.E.G.; ALVES, D.A.; QUEIROZ, D.S. Nutriente limitante ao crescimento do Cenchrus ciliaris variedades Áridus e 131. In: REUNIÃO ANUAL DA SOCIEDADE BRASILEIRA DE ZOOTECNIA, 2009, 46., Maringá. Anais... Maringá: SBZ, 2009a. 3p.

VITOR, C.M.T.; PORTO, E.M.V.; SILVA, M.F.; LIMA, M.V.G.; PEREIRA, M.E.G.; ALVES, D.A.; QUEIROZ, D.S. Nutrientes limitantes ao crescimento do Cenchrus ciliaris variedades Áridus e 131. In: REUNIÃO ANUAL DA SOCIEDADE BRASILEIRA DE ZOOTECNIA, 2009, 46., Maringá. Anais... Maringá: SBZ, 2009b. 3p. 